\title{
KRAS exon 2 codon 13 mutation is associated with a better prognosis than codon 12 mutation following lung metastasectomy in colorectal cancer
}

\author{
Stéphane Renaud ${ }^{1,2,3}$, Francesco Guerrera ${ }^{1,4}$, Joseph Seitlinger ${ }^{1}$, Lorena Costardi ${ }^{4}$, \\ Mickaël Schaeffer ${ }^{5}$, Benoit Romain ${ }^{3,6}$, Claudio Mossetti ${ }^{4}$, Anne Claire-Voegeli ${ }^{7}$, Pier \\ Luigi Filosso ${ }^{4}$, Michèle Legrain7, Enrico Ruffini ${ }^{4}$, Pierre-Emmanuel Falcoz ${ }^{1}$, Alberto \\ Oliaro $^{4}$, Gilbert Massard ${ }^{1}$ \\ ${ }^{1}$ Department of Thoracic Surgery, Strasbourg University Hospital, Strasbourg, France \\ ${ }^{2}$ Department of Thoracic Surgery, Nancy University Hospital, Nancy, France \\ ${ }^{3}$ Research Unit EA3430, Tumoral Progression and Micro-Environment, Epidemiological and Translational Approaches, \\ Strasbourg University, Strasbourg, France \\ ${ }^{4}$ Department of Thoracic Surgery, Azienda Ospedaliera Universitaria Città della Salute e della Scienza di Torino, Torino, Italy \\ ${ }^{5}$ Department of Biostatistics, Strasbourg University Hospital, Strasbourg, France \\ ${ }^{6}$ Department of General and Digestive Surgery, Strasbourg University Hospital, Strasbourg, France \\ ${ }^{7}$ Department of Molecular Biology, Strasbourg University Hospital, Strasbourg, France
}

Correspondence to: Stéphane Renaud, email: sterenaud0@gmail.com

Keywords: lung metastasectomy, colorectal cancer, KRAS, surgery, codon

Received: August 25, $2016 \quad$ Accepted: November 21, $2016 \quad$ Published: November 29, 2016

\section{ABSTRACT}

Introduction: The utilization of molecular markers as routinely used biomarkers is steadily increasing. We aimed to evaluate the potential different prognostic values of KRAS exon 2 codons 12 and 13 after lung metastasectomy in colorectal cancer (CRC).

Results: KRAS codon 12 mutations were observed in 116 patients $(77 \%)$, whereas codon 13 mutations were observed in 34 patients ( $23 \%$ ). KRAS codon 13 mutations were associated with both longer time to pulmonary recurrence (TTPR) (median TTPR: 78 months (95\% CI: 50.61-82.56) vs 56 months (95\% CI: 68.71-127.51), $P=0.008$ ) and improved overall survival (OS) (median OS: 82 months vs 54 months (95\% CI: 48.93-59.07), $P=0.009$ ). Multivariate analysis confirmed that codon 13 mutations were associated with better outcomes (TTPR: HR: 0.40 ( $95 \%$ CI: 0.17-0.93), $P=0.033)$; OS: HR: $0.39(95 \%$ CI: 0.14-1.07), $P=0.07)$. Otherwise, no significant difference in OS $(P=0.78)$ or TTPR $(P=0.72)$ based on the type of amino-acid substitutions was observed among KRAS codon 12 mutations.

Materials and Methods: We retrospectively reviewed data from 525 patients who underwent a lung metastasectomy for CRC in two departments of thoracic surgery from 1998 to 2015 and focused on 150 patients that had KRAS exon 2 codon 12/13 mutations.

Conclusions: KRAS exon 2 codon 13 mutations, compared to codon 12 mutations, seem to be associated with better outcomes following lung metastasectomy in CRC. Prospective multicenter studies are necessary to fully understand the prognostic value of KRAS mutations in the lung metastases of CRC. 


\section{INTRODUCTION}

Colorectal cancer (CRC) remains one of the most diagnosed cancers and one of the leading causes of cancerrelated deaths worldwide $[1,2]$. Because the liver and lungs offer a favorable environment for CRC cells, up to $50 \%$ of the patients will experience metastases in these two locations [3]. Although still the subject of debate, lung metastasectomy is widely accepted by most surgical teams because, in selected populations, it leads to longer overall survival (OS) than conventional 5-fluorouracil (5-FU)based chemotherapy regimens [4-6].

Several risk factors for poor outcomes have been identified to properly select patients who would clearly benefit from surgery, both in terms of OS and disease-free survival (DFS). Moreover, recent meta-analyses have helped to define main clinical prognostic factors [7]; in the past few years, there has been an increased understanding of the molecular alterations in cancer cells, with the identification of oncogenic drivers, suggesting that clinical factors could be a reflection of only gene mutations. These observations support the perspective of a molecular classification of patients, which carries with it the possibility of a better selection process for good surgical candidates [8-11].

In $\mathrm{CRC}$, two proto-oncogenes have been extensively studied: V-Ki-ras2 Kirsten rat sarcoma viral oncogene homolog $(K R A S)$ and $V$-raf murine sarcoma viral oncogene homolog $B 1(B R A F)$. The prognostic and predictive values of mutations of these two genes in metastatic CRC is now clearly defined, particularly leading to resistance to antiEpidermal Growth Factor Receptor (EGFR) therapies [12]. On the other hand, although a growing number of publications have focused on evaluating the prognostic value of KRAS mutations after lung metastasectomy of CRC, clinical data are still inconsistent [8-11]. Furthermore, clinical studies on lung metastases of CRC seem to provide only a fleeting glimpse of what the extent the molecular biology of cancer cells could offer in our daily practice. Particularly, the tumoral heterogeneity of $K R A S$ mutations remains intriguing. Indeed, recently published data have highlighted the existence of two distinct groups of $K R A S$ cells: $K R A S$-dependent and $K R A S$ independent cells [13]. Moreover, it seems that according to KRAS amino-acid substitution, different downstream signaling pathways are activated [14], likely leading to different clinical behaviors such as different degrees of aggressiveness [15], different sites of metastasis [16] and/ or different sensitivity to chemotherapy [17] and radiation therapy 18. Hence, few studies on metastatic CRC tried to evaluate the prognostic significance of KRAS codon 12 and codon 13 mutations, with contradictory results [19-22]. However, to the best of our knowledge, this axis has not been yet investigated in lung metastases of CRC.

We thereby aimed to evaluate the different prognostic value of $K R A S$ exon 2 codon 12 over codon 13 mutations in a large surgical cohort of resected lung metastases.

\section{RESULTS}

According to the selection criteria, 150 patients with lung metastasis of CRC harboring KRAS mutations were included in this study. The clinical-pathological characteristics of these patients are displayed in Table 1. Median follow-up time was 56 months (IQR: 44).

Analyses of $K R A S$ codon 12 transversions revealed 12 (8\%) G12C, 39 (26\%) G12V and 7 (5\%) G12A. Analyses of KRAS codon 12 transitions revealed $49(33 \%)$ G12D and 9 (6\%) G12S. For KRAS codon 13, 34 (23\%) cases of G13D transition were observed.

\section{Clinicopathological variables and $K R A S$ mutations}

Table 1 shows the distribution of clinicopathologic variables according to $K R A S$ codon mutation.

\section{Survival analyses}

Ninety-five patients (63\%) were reported to be alive, and 55 patients $(37 \%)$ were dead during the follow-up period. Overall, the five-year survival rate was $42 \%$. Survival analysis by KRAS codon mutation showed a non-significant difference between codon 12 and codon 13 mutations (median OS (mOS): 84 months vs 82 months, respectively; $P=0.167$ ). However, bevacizumab showed a survival benefit when used in case of KRAS codon 12 mutations (mOS: Not reached (NR) vs 54 months, $P<0.001$ ), but not in KRAS codon 13 mutations (mOS: NR vs 82 months; $P=0.48$ ). Patients were then further analyzed with the exclusion of patients treated with bevacizumab. Hence, survival analysis in patients not treated with bevacizumab showed a significant difference between codon 12 and codon 13 mutations (mOS: 54 months vs 82 months, respectively; $P=0.009$ - Figure 1). Otherwise, because among KRAS codon 12 mutations, G12D and G12V were the most frequent, other codon 12 mutations were pooled in the "other codon 12 mutations" group. There was no significant difference in mOS among KRAS codon 12 mutations (mOS: G12D 55, months (95\% CI: 47.8-62) vs G12V, 55 months (95\% CI 38.63-71.38) vs other codon 12 mutations, 53 months (95\% CI 36.29-69.71); $P=0.78$ ).

Because Food and Drug Administration approval of FOLFOX and bevacizumab in CRC were both obtained in 2004, we decided to compare OS between patients who underwent a lung metastasectomy before and after 2004. The median OS of patients included before $2004(n=100)$ was not significantly different from those included thereafter $(n=50)$ (median OS: 75 months (95\% CI: $55.25-92.68)$ vs 83 months (95\% CI: 72.32-102.18), respectively, $p=0.22$ )

Finally, in univariate analysis, male gender $(P=0.039)$, CCI $(P<0.001)$, WHO performance status $P<0.025)$, pT of CRC $(P<0.001)$, DFS $(P=0.006)$, thoracic LNI $(P<0.001)$ and liver metastasis $P<0.001)$ 
Table 1: Demographic data and main covariates according to $K R A S$ mutational status

\begin{tabular}{|c|c|c|c|c|c|c|c|}
\hline & \multicolumn{2}{|c|}{ Total $(n=150)$} & \multicolumn{2}{|c|}{ Codon $12(n=116)$} & \multicolumn{2}{|c|}{ Codon $13(n=34)$} & \multirow[t]{2}{*}{$P$} \\
\hline & No. & $\%$ & No. & Col \% & No. & Col \% & \\
\hline Bevacizumab (Yes) & 37 & 25 & 27 & 23 & 10 & 29 & 0.465 \\
\hline Age (Mean; SD) & 64 & 8 & 64 & 8 & 65 & 9 & 0.713 \\
\hline Sex (male) & 83 & 55 & 67 & 58 & 16 & 47 & 0.328 \\
\hline Median follow-up time (Median, IQR) & 56 & 44 & 55 & 43 & 58 & 47 & 0.89 \\
\hline $\operatorname{CCI}\left({ }^{*} n=149\right)$ & & & & & & & 0.115 \\
\hline 0 & 41 & 28 & 34 & 29 & 7 & 21 & \\
\hline $1-2$ & 56 & 38 & 38 & 33 & 18 & 55 & \\
\hline $3-4$ & 31 & 21 & 25 & 22 & 6 & 18 & \\
\hline$>=5$ & 21 & 14 & 19 & 16 & 2 & 6 & \\
\hline WHO-PS & & & & & & & 0.708 \\
\hline 0 & 112 & 75 & 85 & 73 & 27 & 79 & \\
\hline 1 & 34 & 23 & 27 & 23 & 7 & 21 & \\
\hline 2 & 3 & 2 & 3 & 3 & & & \\
\hline 3 & 1 & 1 & 1 & 1 & & & \\
\hline Site of primary CRC & & & & & & & 0.489 \\
\hline Colon & 74 & 49 & 59 & 51 & 15 & 44 & \\
\hline Rectum & 76 & 51 & 57 & 49 & 19 & 56 & \\
\hline pT CRC $(* n=148)$ & & & & & & & 0.61 \\
\hline $\mathrm{I}$ & 16 & 11 & 12 & 11 & 4 & 12 & \\
\hline II & 21 & 14 & 14 & 12 & 7 & 21 & \\
\hline III & 88 & 59 & 69 & 61 & 19 & 56 & \\
\hline IV & 23 & 16 & 19 & 17 & 4 & 12 & \\
\hline pN CRC $\left({ }^{*} n=148\right)$ & & & & & & & 0.007 \\
\hline 0 & 87 & 59 & 64 & 56 & 23 & 68 & \\
\hline N1 & 31 & 21 & 29 & 25 & 2 & 6 & \\
\hline $\mathrm{N} 2$ & 28 & 19 & 21 & 18 & 7 & 21 & \\
\hline N3 & 2 & 1 & & & 2 & 6 & \\
\hline CEA $\left({ }^{*} n=143\right)$ & & & & & & & 0.584 \\
\hline $0-5 \mathrm{ng} / \mathrm{ml}$ & 94 & 66 & 71 & 65 & 23 & 70 & \\
\hline$>5 \mathrm{ng} / \mathrm{ml}$ & 49 & 34 & 39 & 35 & 10 & 30 & \\
\hline Chemotherapy & & & & & & & 0.062 \\
\hline None & 39 & 26 & 29 & 25 & 10 & 29 & \\
\hline Peri-operative & 27 & 18 & 16 & 14 & 11 & 32 & \\
\hline Post-operative & 48 & 32 & 41 & 35 & 7 & 21 & \\
\hline Pre-operative & 36 & 24 & 30 & 26 & 6 & 18 & \\
\hline \multicolumn{8}{|l|}{ Side of metastasis } \\
\hline Bilateral & 39 & 26 & 30 & 26 & 9 & 26 & \\
\hline Unilateral & 111 & 74 & 86 & 74 & 25 & 74 & \\
\hline DFS (> 12 months) & 121 & 81 & 95 & 82 & 26 & 76 & 0.481 \\
\hline DFS (24 months) & 92 & 61 & 73 & 63 & 19 & 56 & 0.458 \\
\hline Number of lung metastases $(>1)$ & 76 & 51 & 57 & 49 & 19 & 56 & 0.489 \\
\hline Thoracic LNI $(\mathrm{N}+; n=148)$ & 48 & 32 & 39 & 34 & 9 & 26 & 0.397 \\
\hline
\end{tabular}




\begin{tabular}{|l|l|l|l|l|l|l|l|}
\hline Liver Metastasis & 24 & 16 & 19 & 16 & 5 & 15 & 0.815 \\
\hline KRAS mutation subtype & & & & & & & \\
\hline G12A & 7 & 5 & 7 & 6 & & & \\
\hline G12C & 12 & 8 & 12 & 10 & & & \\
\hline G12D & 49 & 33 & 49 & 42 & & & \\
\hline G12S & 9 & 6 & 9 & 8 & & & \\
\hline G12V & 39 & 26 & 39 & 34 & & & \\
\hline G13D & 34 & 23 & & & 34 & 100 & \\
\hline
\end{tabular}

*number of patients for whom the corresponding data were available. CCI: Charlson Comorbidity Index, WHO-PS: World Health Organization performance status, CRC: colorectal cancer, CEA: carcinoembryonic antigen, DFS: disease free survival, LNI: lymph node involvement, IQR: inter-quartile range.

were found to have a negative effect on survival. Data are shown in Table 2.

Patients who had benefited from bevacizumab were excluded from the multivariate analysis to exclude the effect of bevacizumab on the OS of KRAS codon 12 patients. Hence, the multivariate-adjusted model showed that $\mathrm{CCI}$ and $\mathrm{pT}$ of primary $\mathrm{CRC}$ were independent negative predictors of survival. Finally, there was a trend toward improved OS in KRAS codon 13 mutations $(\mathrm{HR}=0.386, P=0.068)$. Data are displayed in Table 2.

\section{Time to pulmonary recurrence (TTPR)}

One hundred forty patients (93\%) were available for the TTPR analysis; 68 patients (48\%) experienced a lung recurrence during the follow-up period. Overall, the 5-year TTPR rate was $45 \%$. TTPR analysis by KRAS codon mutation showed a significant difference between codon 12 (Median TTPR (mTTPR): 60 months) and codon 13 mutations (mTTPR: NR; $P=0.041$ ). However, bevacizumab showed a benefit on TTPR when used in the case of KRAS codon 12 mutations (mTTPR: 86 (95\% CI: $57-115$ ) vs 30 months (95\% CI: 12-48), $P<0.001)$, but not in KRAS codon 13 mutations (mTTPR: 31 (95\% CI: 15-47) vs 46 months (95\% CI: 1379.18), $P=0.39$ ). Patients were then further analyzed, with the exclusion of patients treated with bevacizumab. Likewise, TTPR analysis in patients not treated with bevacizumab showed a significant difference between codon 12 (mTTPR: 51 months) and codon 13 mutations (mTTPR: NR; $P=0.008$ - Figure 2). Otherwise, among $K R A S$ codon 12 mutations, even shorter in case of G12V transversion (mTTPR: 21 months, $95 \%$ CI: 0-43), there was no significant difference with G12D transition (50 months, 95\% CI: 42-58) and "other codon 12 mutations" (30 months, $95 \%$ CI: $0-68, P=0.72$ ).

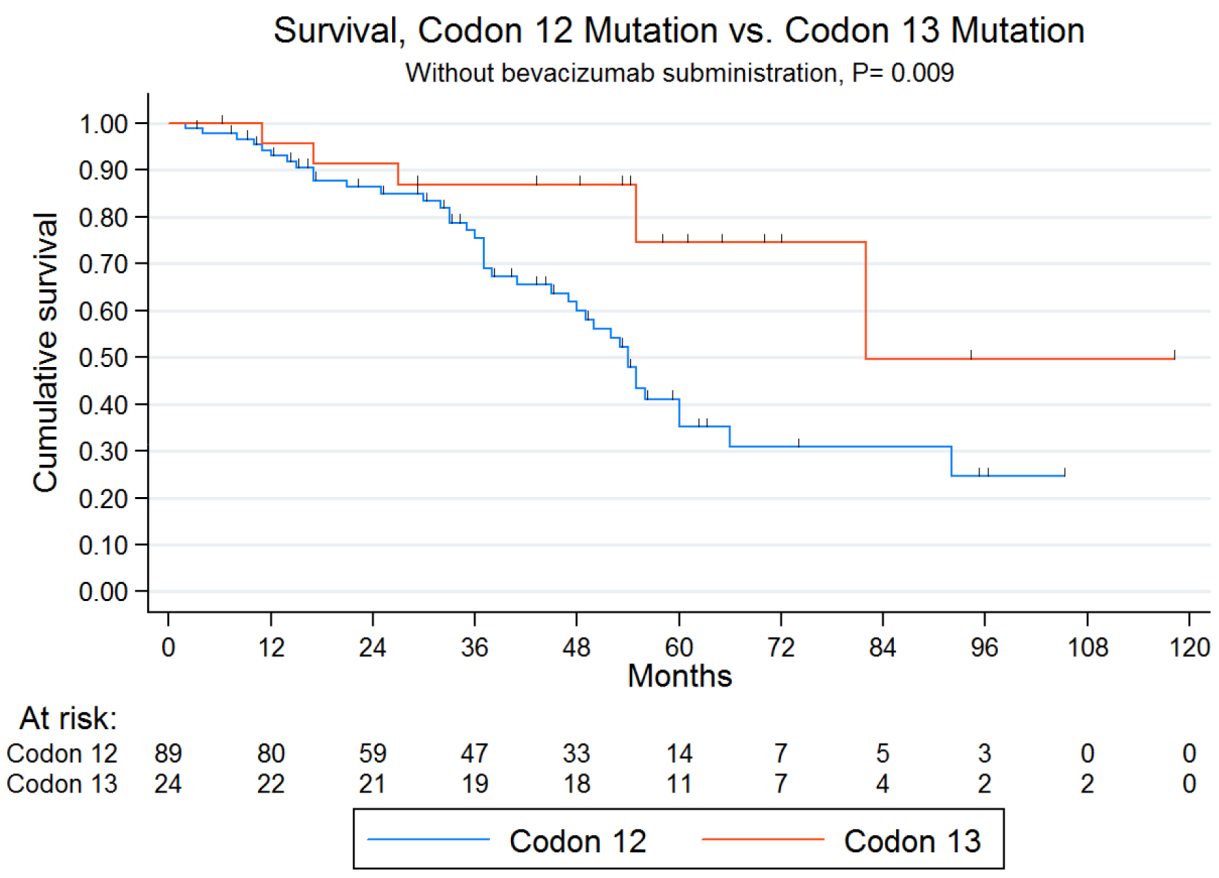

Figure 1: Kaplan-meier overall survival according to codon 12 or 13 mutations in patients not treated with bevacizumab. 
Table 2: Uni- and multivariate analysis on overall survival (OS)

\begin{tabular}{|c|c|c|c|c|c|c|c|c|c|}
\hline $\begin{array}{l}\text { UNIVARIATE } \\
\qquad(N=150)\end{array}$ & $\begin{array}{l}\text { Median survival } \\
\quad \text { (months) }\end{array}$ & $P$ & $\begin{array}{r}{[950} \\
\text { Int }\end{array}$ & $\begin{array}{l}\text { Conf. } \\
\text { Val] }\end{array}$ & $\begin{array}{c}\text { MULTIVARIATE } \\
\text { (without bevacizumab; } \\
\quad N=113 \text { ) }\end{array}$ & $\begin{array}{l}\text { Hazard } \\
\text { Ratio }\end{array}$ & $P$ & & \\
\hline & & & & & & & & & \\
\hline Codon 12 & 84 & & 51 & 116 & & & & & \\
\hline Codon 13 & 82 & & - & - & & & & & \\
\hline Bevacizumab & & $<0.001$ & & & & & & & \\
\hline No & 56 & & 54 & 82 & & & & & \\
\hline Yes & 101 & & 84 & - & & & & & \\
\hline $\begin{array}{l}\text { Mutation subtype } \\
\text { without bevacizumab } \\
(n=113)\end{array}$ & & 0.009 & & & Mutation subtype & & & & \\
\hline Codon 12 & 54 & & 47 & 60 & Codon 12 & 1 & & & \\
\hline Codon 13 & 82 & & 55 & - & Codon 13 & 0.386 & 0.068 & 0.14 & 1.07 \\
\hline Age & & 0.112 & & & Age & & & & \\
\hline$<60$ & 92 & & 92 & - & $<60$ & 1 & & & \\
\hline$>=60$ & 82 & & 55 & 101 & $>=60$ & 1.349 & 0.453 & 0.62 & 2.94 \\
\hline Sex & & 0.039 & & & Sex & & & & \\
\hline Female & NR & & 84 & - & Female & 1 & & & \\
\hline Male & 82 & & 55 & - & Male & 1.195 & 0.645 & 0.56 & 2.55 \\
\hline CCI & & $<0.001$ & & . & $\mathrm{CCI}$ & & & & \\
\hline 0 & 101 & & 84 & - & 0 & 1 & & & \\
\hline $1-2$ & NR & & 55 & - & $1-2$ & 5.063 & 0.020 & 1.28 & 19.96 \\
\hline $3-4$ & 54 & & 35 & - & $3-4$ & 8.995 & 0.003 & 2.06 & 39.22 \\
\hline$>=5$ & 17 & & 17 & - & $>=5$ & 23.415 & 0.001 & 3.41 & 160.69 \\
\hline WHO-PS & & 0.025 & & - & WHO-PS & & & & \\
\hline 0 & 92 & & 66 & - & 0 & 1 & & & \\
\hline 1 & 82 & & 45 & - & 1 & 0.988 & 0.977 & 0.43 & 2.24 \\
\hline 2 & 33 & & 33 & - & 2 & 5.602 & 0.163 & 0.49 & 62.89 \\
\hline 3 & NR & & - & - & 3 & & & & \\
\hline Site of primary CRC & & 0.819 & & & & & & & \\
\hline Colon & NR & & 55 & - & & & & & \\
\hline Rectum & 84 & & 60 & 101 & & & & & \\
\hline pT Colon & & $<0.001$ & & & pT Colon & & & & \\
\hline $\mathrm{T} 1$ & NR & & 52 & - & $\mathrm{T} 1$ & 1 & & & \\
\hline $\mathrm{T} 2$ & 82 & & 47 & - & $\mathrm{T} 2$ & 4.691 & 0.075 & 0.85 & 25.79 \\
\hline $\mathrm{T} 3$ & 84 & & 60 & - & $\mathrm{T} 3$ & 1.857 & 0.406 & 0.43 & 7.99 \\
\hline $\mathrm{T} 4$ & 27 & & 17 & 32 & $\mathrm{~T} 4$ & 9.190 & 0.029 & 1.25 & 67.49 \\
\hline pN Colon & & 0.066 & & & & & & & \\
\hline No & 82 & & 55 & - & & & & & \\
\hline N1 & 60 & & 33 & 84 & & & & & \\
\hline $\mathrm{N} 2$ & NR & & - & - & & & & & \\
\hline N3 & NR & & - & - & & & & & \\
\hline CEA & & 0.092 & & & CEA & & & & \\
\hline $0-5 \mathrm{ng} / \mathrm{m}$ & 82 & & 55 & - & $0-5 \mathrm{ng} / \mathrm{m}$ & 0.895 & 0.779 & 0.41 & 1.94 \\
\hline$>5 \mathrm{ng} / \mathrm{ml}$ & 92 & & 84 & - & $>5 \mathrm{ng} / \mathrm{ml}$ & 1 & & & \\
\hline Chemotherapy & & 0.629 & & & & & & & \\
\hline
\end{tabular}




\begin{tabular}{|c|c|c|c|c|c|c|c|c|c|}
\hline None & 82 & & 55 & - & & & & & \\
\hline Peri-operative & NR & & 37 & - & & & & & \\
\hline Post-operative & 92 & & 55 & - & & & & & \\
\hline Pre-operative & 60 & & 37 & 84 & & & & & \\
\hline Side of surgery & & 0.401 & & & & & & & \\
\hline Unilateral & 82 & & 60 & - & & & & & \\
\hline Bilateral & 101 & & 38 & - & & & & & \\
\hline Disease free survival & & 0.004 & & & Disease free survival & & & & \\
\hline$<24$ months & 101 & & 82 & - & $<24$ months & 1 & & & \\
\hline$>=24$ months & 56 & & 53 & 92 & $>=24$ months & 1.561 & 0.269 & 0.71 & 3.44 \\
\hline $\begin{array}{l}\text { Number of lung } \\
\text { metastasis }\end{array}$ & & 0.457 & & & & & & & \\
\hline 1 & 101 & & 60 & - & & & & & \\
\hline$>1$ & 82 & & 55 & 92 & & & & & \\
\hline Thoracic LNI & & $<0.001$ & & & Thoracic LNI & & & & \\
\hline No & 92 & & 82 & - & No & 1 & & & \\
\hline Yes & 50 & & 37 & 56 & Yes & 2.075 & 0.104 & 0.86 & 5.01 \\
\hline Liver Metastasis & & $<0.001$ & & & Liver Metastasis & & & & \\
\hline No & 84 & & 82 & - & No & 1 & & & \\
\hline Yes & 47 & & 37 & - & Yes & 1.509 & 0.379 & 0.61 & 3.77 \\
\hline
\end{tabular}

CCI: Charlson Comorbidity Index, WHO: World Health Organization Performance Status, CRC: colorectal cancer, CEA: carcinoembryonic antigen, DFS: disease free survival, LNI: lymph node involvement.

Finally, in univariate analysis, the primary CRC site $(P=0.033)$, pT of CRC $(P<0.001)$, side of lung metastasis $(P<0.001)$, thoracic LNI $(P=0.015)$ and liver metastasis $(P=0.002)$ were found to have a negative effect on TTPR. Data are shown in Table 3.

Patients who had benefited from bevacizumab were excluded from the multivariate analysis to exclude the effect of bevacizumab on the mTTPR of KRAS codon 12 patients. Hence, at multivariate analysis, pT of CRC, side of lung metastasis and liver metastasis demonstrated an independent negative effect on TTPR. Moreover, an independent effect on improved TTPR in KRAS codon 13 mutations was observed (HR 0.40, $P=0.033$ ). Data are shown in Table 3.

\section{DISCUSSION}

In vitro studies suggest a wide heterogeneity of $K R A S$ mutations, suggesting different prognostic values of exon 2 codon 12 and codon 13 mutations. More specifically, exon 2 codon 12 mutations, in particular, G12D and G12V mutations, seem to be able to induce a more robust link with GTP molecules leading to higher resistance to GTPase activity compared to codon 13 mutations, in particular, G13D [23, 24]. On the other hand, it seems that KRAS codon 12 mutations, but not codon 13 mutations, are associated with a strong upregulation of vascular endothelial growth factor (VEGF) $[24,25]$, which is implicated in the promotion of lymphangiogenesis [26], which seems to be related to recurrence and decreased OS after lung metastasectomy in CRC [26]. These two observations suggest a higher aggressiveness of codon 12 mutations over codon 13 mutations. Although there have been no published data on the prognostic value of exon 2 codon mutations after lung metastasectomy in CRC to date, several authors have previously attempted to investigate its value in metastatic CRC. However, few data are available, and the studied populations have been heterogeneous, including all stages of CRC. In a collaborative study including 3439 CRC patients, Andreyev et al. [20] found a significant association between $\mathrm{G} 12 \mathrm{~V}$ mutation and both failurefree survival (HR: 1.3, $P=0.004$ ) and OS (HR: 1.29, $P=0.008)$. However, the impact of this mutation was only observed in Duke's C stage, but not in Duke's B or in an advanced stage. In another work, Imamura et al. [21] confirmed in $1075 \mathrm{CRC}$ patients the association between G12V mutation and worse OS (HR: $2.00 P=0.0003$ ), but without significant impact on prognosis of codon 13 mutations. In contrast, Samowitz et al. [22], in a large study of 1413 patients, although non-significant, found a $40 \%$ increase in short-term mortality from CRC in the case of codon 13 mutations. More recently, among 218 metastatic CRC patients, Dadduzio et al. [19] did not find any prognostic difference between codon 12 and codon 13 mutations. To the best of our knowledge, our study is the first to focus on the prognostic value of these 2 codon mutations after lung metastasectomy in CRC. Consistent with in vitro studies, our work suggests a higher aggressiveness of codon 12 over codon 
Table 3: Uni- and multivariate analysis on time to pulmonary recurrence (TTPR)

\begin{tabular}{|c|c|c|c|c|c|c|c|c|c|}
\hline $\begin{array}{l}\text { UNIVARIATE } \\
\quad(N=140)\end{array}$ & $\begin{array}{c}\text { Median } \\
\text { TTPR } \\
\text { (months) }\end{array}$ & $P$ & $\begin{array}{r}{\left[95^{\circ}\right.} \\
\text { In }\end{array}$ & & $\begin{array}{c}\text { MULTIVARIATE } \\
\text { (without } \\
\text { bevacizumab; } \\
N=113 \text { ) }\end{array}$ & $\begin{array}{c}\text { Hazard } \\
\text { ratio }\end{array}$ & $\boldsymbol{P}$ & $\begin{array}{r}{[95 \%} \\
\text { Int }\end{array}$ & $\begin{array}{l}\text { Conf. } \\
\text { val] }\end{array}$ \\
\hline Mutation subtype & & 0.041 & & & & & & & \\
\hline Codon 12 & 60 & & 51 & 86 & & & & & \\
\hline Codon 13 & NR & & 50 & - & & & & & \\
\hline Bevacizumab & & 0.049 & & & & & & & \\
\hline No & 51 & & 50 & 100 & & & & & \\
\hline Yes & 92 & & 70 & 98 & & & & & \\
\hline $\begin{array}{l}\text { Mutation } \\
\text { subtype without } \\
\text { bevacizumab } \\
(n=113)\end{array}$ & & 0.009 & & & $\begin{array}{l}\text { Mutation } \\
\text { subtype without } \\
\text { bevacizumab } \\
(n=113) \\
\end{array}$ & & & & \\
\hline Codon 12 & 51 & & 41 & 60 & Codon 12 & 1 & & & \\
\hline Codon 13 & NR & & 50 & - & Codon 13 & 0.40 & 0.033 & 0.17 & 0.93 \\
\hline Age & & 0.891 & & & & & & & \\
\hline$<60$ & 86 & & 50 & - & & & & & \\
\hline$>=60$ & 60 & & 51 & 98 & & & & & \\
\hline$\overline{\operatorname{Sex}}$ & & 0.206 & & & & & & & \\
\hline Female & 70 & & 51 & 100 & & & & & \\
\hline Male & 57 & & 51 & - & & & & & \\
\hline $\begin{array}{l}\text { Site of primary } \\
\text { CRC }\end{array}$ & & 0.033 & & & $\begin{array}{l}\text { Site of primary } \\
\text { CRC }\end{array}$ & & & & \\
\hline Colon & 51 & & 49 & 70 & Colon & 1.29 & 0.440 & 0.67 & 2.48 \\
\hline Rectum & 86 & & 60 & 98 & Rectum & 1 & & & \\
\hline pT Colon & & $<0.001$ & & & pT Colon & & & & \\
\hline $\mathrm{T} 1$ & 98 & & 51 & 112 & $\mathrm{~T} 1$ & 1 & & & \\
\hline $\mathrm{T} 2$ & NR & & 20 & - & $\mathrm{T} 2$ & 8.14 & 0.016 & 1.47 & 45.11 \\
\hline T3 & 60 & & 51 & 86 & T3 & 5.17 & 0.017 & 1.34 & 19.86 \\
\hline $\mathrm{T} 4$ & 15 & & 12 & 24 & $\mathrm{~T} 4$ & 24.19 & $<0.001$ & 5.11 & 114.65 \\
\hline pN Colon & & 0.529 & & & & & & & \\
\hline N0 & 57 & & 50 & 86 & & & & & \\
\hline N1 & NR & & 16 & - & & & & & \\
\hline $\mathrm{N} 2$ & NR & & 51 & - & & & & & \\
\hline N3 & NR & & - & - & & & & & \\
\hline CEA & & 0.283 & & & & & & & \\
\hline $0-5 \mathrm{ng} / \mathrm{m}$ & 60 & & 50 & 86 & & & & & \\
\hline$>5 \mathrm{ng} / \mathrm{ml}$ & 92 & & 51 & 100 & & & & & \\
\hline Chemotherapy & & 0.241 & & & & & & & \\
\hline None & 100 & & 50 & - & & & & & \\
\hline Peri-operative & 57 & & 40 & - & & & & & \\
\hline Post-operative & 86 & & 51 & 98 & & & & & \\
\hline Pre-operative & 70 & & 24 & - & & & & & \\
\hline
\end{tabular}




\begin{tabular}{|c|c|c|c|c|c|c|c|c|c|}
\hline Side of surgery & & $<0.001$ & & & Side of surgery & & & & \\
\hline Unilateral & 112 & & 60 & - & Unilateral & 1 & & & \\
\hline Bilateral & 40 & & 16 & 57 & Bilateral & 5.65 & $<0.001$ & 2.62 & 12.21 \\
\hline $\begin{array}{l}\text { Disease free } \\
\text { survival }\end{array}$ & & 0.489 & & & & & & & \\
\hline$<24$ months & 60 & & 51 & 98 & & & & & \\
\hline$>=24$ months & 70 & & 51 & 112 & & & & & \\
\hline $\begin{array}{l}\text { Number of } \\
\text { nodules }\end{array}$ & & 0.409 & & & & & & & \\
\hline 1 & 70 & & 51 & 98 & & & & & \\
\hline$>1$ & 60 & & 50 & - & & & & & \\
\hline Thoracic LNI & & 0.015 & & & Thoracic LNI & & & & \\
\hline No & 86 & & 60 & 92 & No & 1 & & & \\
\hline Yes & 50 & & 30 & 98 & Yes & 1.86 & 0.101 & 0.89 & 3.89 \\
\hline Liver Metastasis & & 0.002 & & & Liver Metastasis & & & & \\
\hline No & 86 & & 57 & 92 & No & 1 & & & \\
\hline Yes & 44 & & 19 & 49 & Yes & 2.52 & 0.031 & 1.09 & 5.84 \\
\hline
\end{tabular}

CCI: Charlson Comorbidity Index, WHO: World Health Organization Performance Status, CRC: colorectal cancer, CEA: carcinoembryonic antigen, DFS: disease free survival, LNI: lymph node involvement.

13 mutations in terms of both OS and TTPR. Unlike previous authors [20,21], we did not find any significant difference among codon 12 mutations. Indeed, even if $\mathrm{G} 12 \mathrm{~V}$ transversions were associated with decreased TTPR, there was no significant difference with all other types of codon 12 amino-acid substitutions. However, our population was small, and the absence of differences may have been related to a lack of power. Furthermore, the "other codon 12 mutations" group included different types of amino-acid substitutions; behaviors of each type

Time to pulmonary recurrence, Codon 12 Mutation vs. Codon 13 Mutation Without Bevacizumab subministration, $\mathrm{P}=0.008$

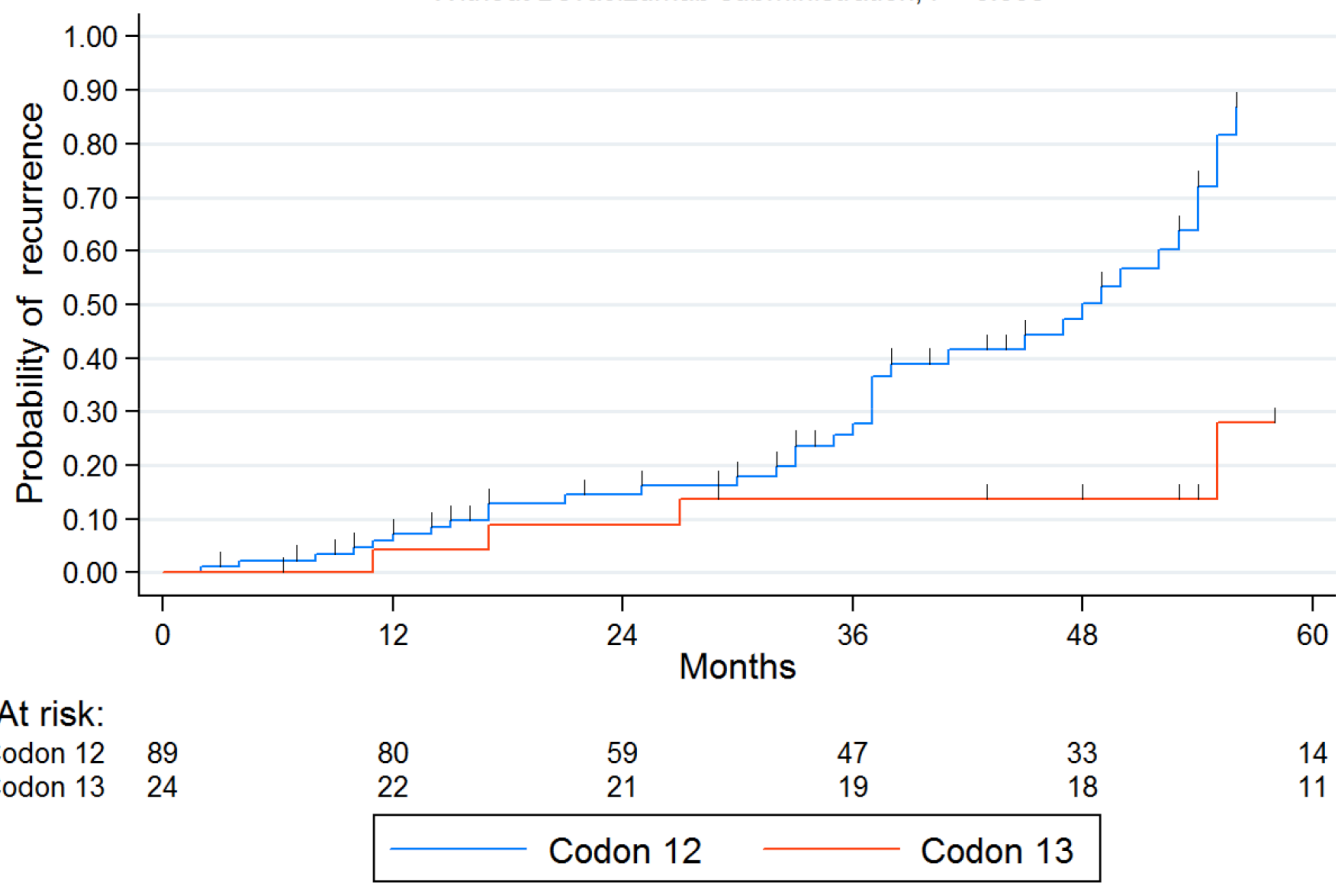

Figure 2: Kaplan-meier time to pulmonary recurrence according to codon 12 or 13 mutations in patients not treated with bevacizumab. 
of amino-acid substitution could not have been studied because of the small number of patients in each group. Indeed, in vitro studies have shown that the type of aminoacid substitution may activate different downstream signaling [14]. Hence, both KRAS G12C and G12V exhibited activated Ral signaling and decreased growth factor-dependent Akt activation, although the G12D mutation exhibited activated PI3K and MEK signaling. Consequently, it would not be surprising that different amino-acid substitutions confer different behavior to cancer cells after lung metastasectomy in CRC with different prognoses as observed in other cancers.

It is usually admitted that rectal cancer cells have a higher tropism to the lung than colon cancer cells. This might be partially explained by a mechanical theory, in which cancer cells can metastasize directly to the lung because of the drainage of the rectum by the rectal veins directly to the lower vena cava, meanwhile colon cancer cells must pass through the portal system and the liver, who plays the role of filter and stop cancer cells, before they can reach the lung. However, previous series have shown that CRC cells harboring KRAS mutations have a higher lung tropism than wild type or cancer cells harboring $B R A F$ mutations [27]. This lung tropism of $K R A S$ mutations may explain why we did not observe in our cohort a higher prevalence of rectal cancer.

As previously published by our team in a singleinstitutional study [28, 27], we confirmed in this multicenter study that bevacizumab may improve both OS and TTPR in patients with KRAS codon 12 mutations, but not with codon 13 mutations.

Finally, in our cohort known prognostic factors, namely thoracic LNI, liver metastases, DFS and preoperative CEA did not significantly impact the OS. These observations may be related to our highly selected population, or on the other hand to the fact that mutational status is statistically more powerful to impact OS than other prognostic factors, and that these prognostic factors, as previously evoked, could be only reflections of mutational status [8].

However, our study must be interpreted with caution regarding a few limitations. First, it is a retrospective cohort study based on a relatively small sample size. Furthermore, 122 patients were from Strasbourg cohort, probably leading to a center effect. However, to the best of our knowledge, this is the largest published cohort on $K R A S$ mutations in lung metastases of $\mathrm{CRC}$, and a multicentre cohort seemed necessary to obtain enough statistical power in this highly selected population. Furthermore, our study covers a 17-year period during which there may have been changes in the management of patients; the different chemotherapy regimens used may have also influenced the survival of the study participants. However, a long study period was required to obtain enough statistical power. However, we did not observe a survival difference before and after FOLFOX and bevacizumab introduction. Furthermore, the molecular data were obtained from the primary $\mathrm{CRC}$ and not from the metastatic tumors. Consequently, there is remaining doubt regarding the degree of concordance between the primary and metastatic tumors, although Cejas et al. [29] reported a concordance rate of $94 \%$. Finally, data on extra-thoracic recurrence were not available; this would be interesting to investigate in prospective studies.

In conclusion, to the best of our knowledge this is the first work on the largest published cohort of lung metastases with KRAS mutations showing that exon 2 codon 13 mutations harbor both better OS and TTPR compared to codon 12 mutations. This difference is supported by a molecular explanation because codon 12 mutations exhibit higher up-regulation of VEGF and more stable bonds between Ras and GTP. Our study adds more evidence to support that molecular biology may be helpful in our daily practice. To date, only a small portion of the large landscape of KRAS mutations have been explored. Prospective multicenter studies are necessary to understand the role of molecular biology in the proper selection of patients for lung metastasectomy of CRC. In particular, further studies are necessary to clarify the prognostic and predictive value of each KRAS amino-acid substitution.

\section{MATERIALS AND METHODS}

This study was approved by the Ethics Committee of the French Society of Thoracic and Cardiovascular Surgeons (Approval Number: 2016-8-4-21-0-58-ReSt). We retrospectively reviewed the data from 525 unselected and consecutive patients with metastatic CRC who underwent a lung metastasectomy in both the Thoracic Surgery Department of Strasbourg University Hospital (France) and Torino University Hospital (Italy) from January 1998 to December 2015. Patients for whom mutational status was unknown (i.e., $K R A S$ and $B R A F$ ) $(n=92)$, who exhibited a $B R A F$ mutation $(n=26)$, and who did not harbor $K R A S / B R A F$ mutations $(n=257)$ were excluded from this study. All included patients were considered completely cured of their primary tumor at the time of the thoracic metastasectomy, and all pulmonary metastases were metachronous. In cases of extra-thoracic metastases, only patients with hepatic metastases were included. All thoracic resections were considered R0.

Pre-operative thoracic evaluation, lung metastasectomy procedures, covariates and data collection, and molecular analysis of KRAS mutations in codons 12 and 13 were performed as previously published [8].

\section{Covariates and data collection}

Length of DFS was calculated from the surgery of the primary CRC to the first diagnosis of a thoracic or liver metastasis by imaging. OS was calculated from the first metastasectomy until death or the last follow- 
up. Time to pulmonary recurrence (TTPR) was defined as the time period between a thoracic metastasectomy and the first diagnosis of thoracic recurrence. Because patients were referred to our Departments of Thoracic Surgery by various oncologists from different centers, no uniform protocol for chemotherapy was performed. However, chemotherapy regimens generally consisted of fluoropyrimidines (5-fluorouracil (5-FU)), administered alone or in combination with oxaliplatin (Folfox/XelOx regimens) and/or irinotecan (Folfiri/Folfoxiri regimens). In some cases, bevacizumab was added at the discretion of the oncologist. The timing of chemotherapy was defined as follows: neo-adjuvant chemotherapy administered prior to thoracic surgery, adjuvant chemotherapy administered following lung metastasectomy, and POC was performed both in neo-adjuvant and adjuvant settings.

\section{Statistical analysis}

Categorical data are presented as the number (percentage, \%), and continuous data are presented as the mean with standard deviation (SD). Associations between Codon 12 and Codon 13 and clinicalpathological characteristics were assessed with the use of the Mann-Whitney U test for continuous variables and the chi-square test and Fisher's exact test for categorical variables as appropriate. The prognostic influence of predictors on OS and TTPR was assessed with a logrank test and predictors associated with $P \leq 0.2$ on univariate analysis were included in the multivariate models. A multivariate Cox proportional hazard model was employed to estimate the hazard ratios (HR) and 95\% CI for the possible independent predictors of OS and TTR. All the tests were two-sided, and variables were considered significant for $P$ values $<0.05$. Statistical analyses were performed using Stata 13.1 (StataCorp LP, College Station, TX, USA).

\section{CONFLICTS OF INTEREST}

The authors have no conflicts of interests to declare.

\section{REFERENCES}

1. Fitzmaurice C, Dicker D, Pain A, Hamavid H, Moradi-Lakeh M, MacIntyre MF, Allen C, Hansen G, Woodbrook R, Wolfe C, Hamadeh RR, Moore A, Werdecker A, et al. The Global Burden of Cancer 2013. JAMA Oncol. 2015; 1:505-527.

2. Ferlay J, Steliarova-Foucher E, Lortet-Tieulent J, Rosso S, Coebergh JW, Comber H, Forman D, Bray F. Cancer incidence and mortality patterns in Europe: estimates for 40 countries in 2012. Eur J Cancer. 2013; 49:1374-1403.

3. August DA, Ottow RT, Sugarbaker PH. Clinical perspective of human colorectal cancer metastasis. Cancer Metastasis Rev. 1984; 3:303-324.
4. Pfannschmidt J, Hoffmann H, Dienemann H. Reported outcome factors for pulmonary resection in metastatic colorectal cancer. J Thorac Oncol. 2010; 5:S172-178.

5. Sanoff HK, Sargent DJ, Campbell ME, Morton RF, Fuchs CS, Ramanathan RK, Williamson SK, Findlay BP, Pitot HC, Goldberg RM. Five-year data and prognostic factor analysis of oxaliplatin and irinotecan combinations for advanced colorectal cancer: N9741. J Clin Oncol. 2008; 26:5721-5727.

6. Salah S, Watanabe K, Welter S, Park JS, Park JW, Zabaleta J, Ardissone F, Kim J, Riquet M, Nojiri K, Gisabella M, Kim SY, Tanaka K, et al. Colorectal cancer pulmonary oligometastases: pooled analysis and construction of a clinical lung metastasectomy prognostic model. Ann Oncol. 2012; 23:2649-2655.

7. Gonzalez M, Gervaz P. Risk factors for survival after lung metastasectomy in colorectal cancer patients: systematic review and meta-analysis. Future Oncol. 2015; 11:31-33.

8. Renaud S, Romain B, Falcoz PE, Olland A, Santelmo N, Brigand C, Rohr S, Guenot D, Massard G. KRAS and BRAF mutations are prognostic biomarkers in patients undergoing lung metastasectomy of colorectal cancer. Br J Cancer. 2015; 112:720-728.

9. Ghidini M, Personeni N, Bozzarelli S, Baretti M, Basso G, Bianchi P, Tronconi MC, Pressiani T, Grizzi F, Giordano L, Malesci A, Alloisio M, Laghi L, et al. KRAS mutation in lung metastases from colorectal cancer: prognostic implications. Cancer Med. 2016; 5:256-264.

10. Pereira AA, Rego JF, Morris V, Overman MJ, Eng C, Garrett CR, Boutin AT, Ferrarotto R, Lee M, Jiang ZQ, Hoff PM, Vauthey JN, Vilar E, et al. Association between KRAS mutation and lung metastasis in advanced colorectal cancer. Br J Cancer. 2015; 112:424-428.

11. Schweiger T, Hegedüs B, Nikolowsky C, Hegedüs Z, Szirtes I, Mair R, Birner P, Döme B, Lang G, Klepetko W, Ankersmit HJ, Hoetzenecker K. EGFR, BRAF and KRAS status in patients undergoing pulmonary metastasectomy from primary colorectal carcinoma: a prospective followup study. Ann Surg Oncol. 2014; 21:946-954.

12. De Roock W, Claes B, Bernasconi D, De Schutter J, Biesmans B, Fountzilas G, Kalogeras KT, Kotoula V, Papamichael D, LaurentPuig P, Penault-Llorca F, Rougier P, Vincenzi B, et al. Effects of KRAS, BRAF, NRAS, and PIK3CA mutations on the efficacy of cetuximab plus chemotherapy in chemotherapy-refractory metastatic colorectal cancer: a retrospective consortium analysis. The Lancet Oncology. 2010; 11:753-762.

13. Singh A, Greninger P, Rhodes D, Koopman L, Violette S, Bardeesy N, Settleman J. A gene expression signature associated with "K-Ras addiction" reveals regulators of EMT and tumor cell survival. Cancer Cell. 2009; 15:489-500.

14. Ihle NT, Byers LA, Kim ES, Saintigny P, Lee JJ, Blumenschein GR, Tsao A, Liu S, Larsen JE, Wang J, Diao L, Coombes KR, Chen L, et al. Effect of KRAS oncogene substitutions on protein behavior: implications for signaling and clinical outcome. J Natl Cancer Inst. 2012; 104:228-239. 
15. Renaud S, Falcoz PE, Schaëffer M, Guenot D, Romain B, Olland A, Reeb J, Santelmo N, Chenard MP, Legrain M, Voegeli AC, Beau-Faller M, Massard G. Prognostic value of the KRAS G12V mutation in 841 surgically resected Caucasian lung adenocarcinoma cases. Br J Cancer. 2015; 113:1206-1215.

16. Renaud S, Seitlinger J, Falcoz PE, Schaeffer M, Voegeli AC, Legrain M, Beau-Faller M, Massard G. Specific KRAS amino acid substitutions and EGFR mutations predict sitespecific recurrence and metastasis following non-small-cell lung cancer surgery. Br J Cancer. 2016; 115:346-353.

17. Garassino MC, Marabese M, Rusconi P, Rulli E, Martelli O, Farina G, Scanni A, Broggini M. Different types of K-Ras mutations could affect drug sensitivity and tumor behavior in non-small-cell lung cancer. Annals of Oncology. 2011; 22:235-237.

18. Renaud S, Schaeffer M, Voegeli AC, Legrain M, Guérin E, Meyer N, Mennecier B, Quoix E, Falcoz PE, Guénot D, Massard G, Noël G, Beau-Faller M. Impact of EGFR mutations and KRAS amino acid substitution on the response to radiotherapy for brain metastasis of non-small-cell lung cancer. Future Oncol. 2016; 12:59-70.

19. Dadduzio V, Basso M, Rossi S, Cenci T, Capodimonti S, Strippoli A, Orlandi A, Cerchiaro E, Schinzari G, Cassano A, Martini M, Barone C. KRAS Exon 2 Mutations as Prognostic Indicators in Advanced Colorectal Cancer in Clinical Practice: A Mono-Institutional Study. Mol Diagn Ther. 2016; 20:65-74.

20. Andreyev HJ, Norman AR, Cunningham D, Oates J, Dix BR, Iacopetta BJ, Young J, Walsh T, Ward R, Hawkins N, Beranek M, Jandik P, Benamouzig R, et al. Kirsten ras mutations in patients with colorectal cancer: the 'RASCAL II' study. Br J Cancer. 2001; 85:692-696.

21. Imamura Y, Morikawa T, Liao X, Lochhead P, Kuchiba A, Yamauchi M, Qian ZR, Nishihara R, Meyerhardt JA, Haigis KM, Fuchs CS, Ogino S. Specific mutations in KRAS codons 12 and 13, and patient prognosis in 1075 BRAF wild-type colorectal cancers. Clin Cancer Res. 2012; 18:4753-4763.

22. Samowitz WS, Curtin K, Schaffer D, Robertson M, Leppert M, Slattery ML. Relationship of Ki-ras mutations in colon cancers to tumor location, stage, and survival: a population-based study. Cancer Epidemiol Biomarkers Prev. 2000; 9:1193-1197.

23. Al-Mulla F, Milner-White EJ, Going JJ, Birnie GD. Structural differences between valine-12 and aspartate-12 Ras proteins may modify carcinoma aggression. J Pathol. 1999; 187:433-438.

24. Guerrero S, Casanova I, Farre L, Mazo A, Capella G, Mangues R. K-ras codon 12 mutation induces higher level of resistance to apoptosis and predisposition to anchorageindependent growth than codon 13 mutation or protooncogene overexpression. Cancer Res. 2000; 60:6750-6756.

25. Rak J, Mitsuhashi Y, Bayko L, Filmus J, Shirasawa S, Sasazuki T, Kerbel RS. Mutant ras oncogenes upregulate VEGF/ VPF expression: implications for induction and inhibition of tumor angiogenesis. Cancer Res. 1995; 55:4575-4580.

26. Schweiger T, Nikolowsky C, Graeter T, Seebacher G, Laufer J, Glueck O, Glogner C, Birner P, Lang G, Klepetko W, Ankersmit HJ, Hoetzenecker K. Increased lymphangiogenesis in lung metastases from colorectal cancer is associated with early lymph node recurrence and decreased overall survival. Clin Exp Metastasis. 2016; 33:133-141.

27. Lipsyc M, Yager R. Impact of somatic mutations on patterns of metastasis in colorectal cancer. J Gastrointest Oncol. 2015; 6:645-649.

28. Renaud S, Schaeffer M, Falcoz PE, Seitlinger J, Romain B, Voegeli AC, Legrain M, Reeb J, Santelmo N, Rohr S, Brigand C, Olland A, Guenot D, et al. Perioperative bevacizumab improves survival following lung metastasectomy for colorectal cancer in patients harbouring v-Ki-ras2 Kirsten rat sarcoma viral oncogen homolog exon 2 codon 12 mutations. Eur J Cardiothorac Surg. 2016. doi: 10.1093/ejcts/ezw304.

29. Cejas P, López-Gómez M, Aguayo C, Madero R, de Castro Carpeño J, Belda-Iniesta C, Barriuso J, Moreno García V, Larrauri J, López R, Casado E, Gonzalez-Barón M, Feliu J. KRAS mutations in primary colorectal cancer tumors and related metastases: a potential role in prediction of lung metastasis. PLoS One. 2009; 4:e8199. 